\title{
The Effect of Cross Section of Mechanical Flotation Cells on the Height of Turbulent and Quiescent Zones
}

\author{
S .Razmjooei, M. Abdollahy*, M. R. Khalesi, M. Mohseni \\ Department of Mining Engineering, Tarbiat modares university, Tehran, Iran
}

*Corresponding Author: M. Abdollahy Department of Mining Engineering, Tarbiat modares university, Tehran, Iran

\begin{abstract}
A mechanical flotation cell necessitates generation of three distinct hydrodynamic zones for effective flotation. The ratio between the height of turbulent and quiescent zones play a key role in cell efficiency. The effect of impeller speed and size, cell aspect ratio (height of the pulp to cell diameter) and superficial gas velocity on the height of turbulent and quiescent zones have been considered in other research. In this paper, the effect of cell cross section was investigated. The experiments were conducted in a cylindrical cell and two rectangular cells with different cross sections. Piezo electric sensor was applied to determine the height of the turbulent and quiescent zones. Turbulence conditions were changed by varying the impeller speed. In rectangular cells, the height of the turbulent and the quiescent zones was independent of the impeller speed while in the cylindrical cell the height of the turbulent zone increased by increasing the impeller speed. These results are practicable to optimize turbulence in mechanical flotation cells in order to reduce the entrainment and increase the true flotation.
\end{abstract}

Keywords: Turbulent zone, quiescent zone, Mechanical flotation cell

\section{INTRODUCTION}

In a mechanical flotation cell, the formation of three hydrodynamic zones including the turbulent, the quiescent and the froth zone is essential for effective flotation. The turbulent zone affects solids suspension, gas dispersion and bubble-particle interactions. Quiescent zone helps reducing the probability of recovery of gangue minerals, which may have been entrained mechanically. Therefore, better understanding of the height of these zones is essential $[1,2]$. The three hydrodynamic zones in a mechanical cell are depicted in Figure 1.

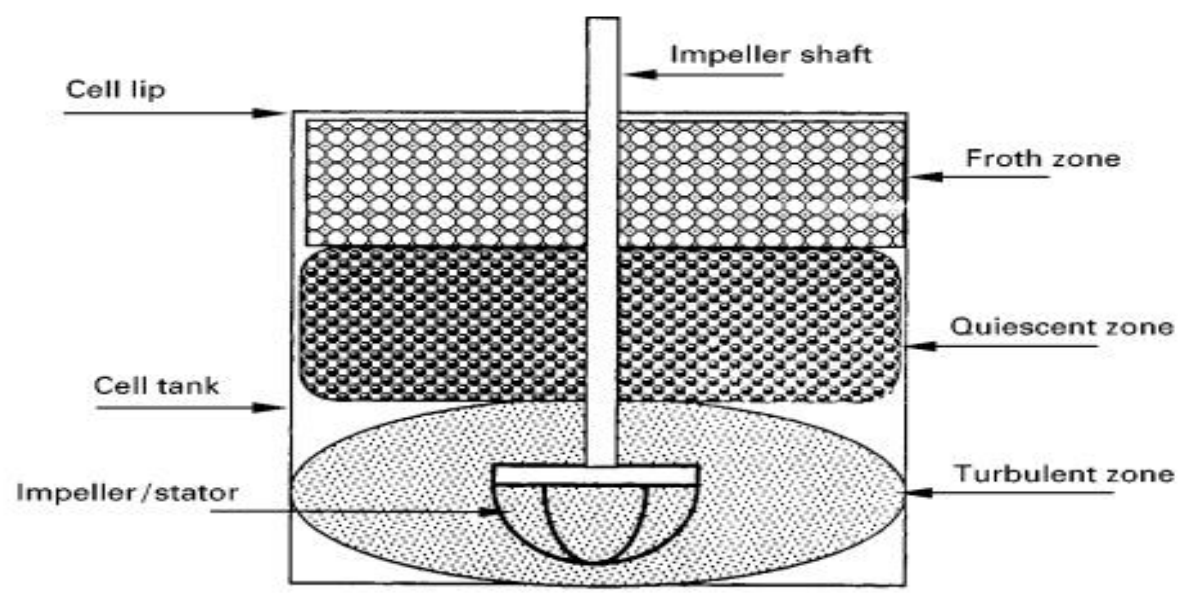

Figure1. Hydrodynamic zones in a mechanical flotation cell [2]

The effect of tank geometry (number of baffles, impeller diameter, and off-bottom clearance) on the maximum turbulence energy dissipation rate for impellers are studied [3]. Tabosa et al. investigated the effect of impeller speed and its size, cell aspect ratio and superficial gas velocity on the height of the turbulent and the quiescent zones [4]. In research work described in this paper, the effect of cell cross-section on both turbulent and quiescent zones is investigated that it has not been considered. 


\section{Methods AND Materials}

In this study, an LDTO-028 piezoelectric sensor was applied to measure the turbulence in the flotation cell as suggested by Meng and et.al [5]. As depicted in Figure 2, the piezoelectric sensor was connected to a rod and it was located in the cell using a mesh surface in order to prevent the sensor vibration and to measure the turbulence at various depths. A filtering integrated circuit, was used as proposed by the sensor manufacturer. Signals were transferred to computer via a 4704 Advantech card. Finally, the analysis of received signals was done by Matlab Signal Processing toolbox. After the signal filtration, the effective voltage, Vrms, was presented as an index for turbulence. Then, the graph of voltage variations against the relative height of the cell was plotted and the border between zones was identified based on the method applied by Tabosa et al [4].

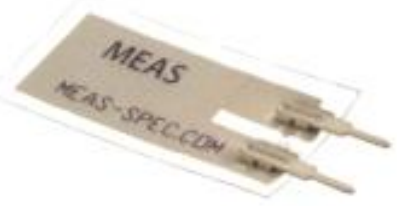

a. MEAS LDT0-028K

piezoelectric film sensor
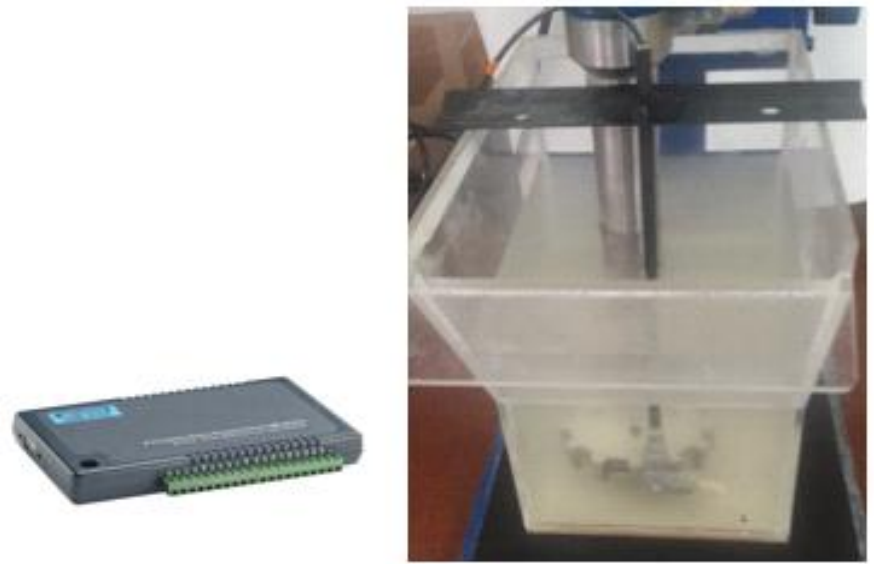

b. 4704 Advantech card c. Flotation cell

Figure2. Measurement setup of piezoelectric sensor

In order to investigate the effect of cell cross-section, a cylindrical cell and two rectangular cells were used. The relative height $(\mathrm{h} / \mathrm{H})$ in rectangular cells $\mathrm{A}$ and $\mathrm{B}$ was 0.3 and 0.4 respectively. The volume of all cells was 9 liter. Experiments were done in the absence of any collector and frother and only in the presence of water. The impeller speed varied in order to change the turbulence. Figure 3 shows a schematic of the cells and the points of sampling.

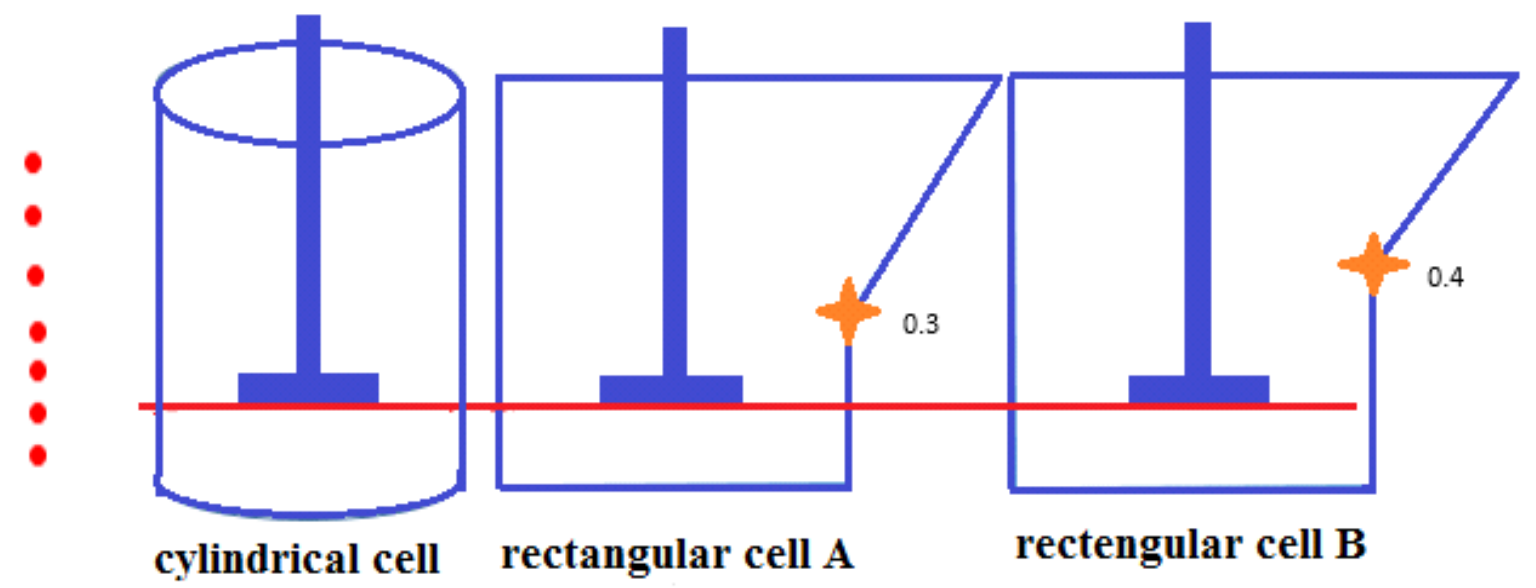

Figure3. Cells and sampling points

\section{RESULTS AND DISCUSSION}

The effect of impeller speed on the height of turbulent and quiescent zones in the cylindrical cell is shown in Figure 4. An increase in the impeller speed caused a big impact on the height of the turbulent zone [4]. According to the results, the height of the turbulent and the quiescent zones are completely dependent on the impeller speed. 


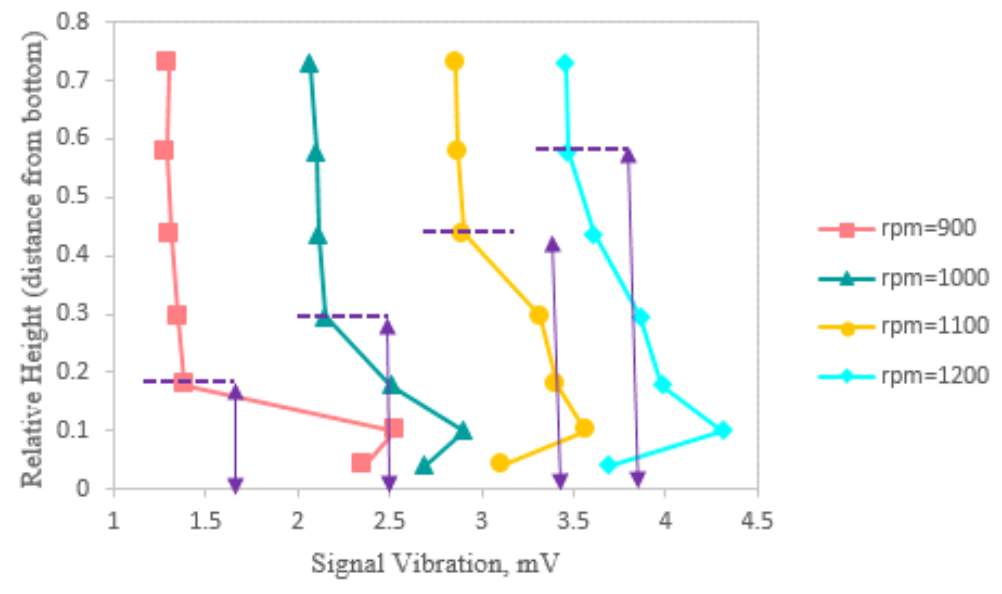

Figure4. Comparison of vibration signal profiles for different impeller speeds in cylindrical cell

The results for rectangular cells A and B are shown in Figure 5 and 6 respectively. In cell A, at all impeller speeds, the maximum turbulence was observed in relative height of 0.1 , then the turbulence decreased and finally in relative height of 0.3 reached a constant value. Relative height of 0.3 for this cell was the place where the cross section of the cell changes. In cell B, a similar trend was observed and the turbulence reached to a constant value in relative height of 0.4 , where the cross section of cell B changes. Therefore, for both cells, it was observed that the border between the quiescent and turbulent zones is independent of the impeller speed and fully depends on the cross-section of the cell. A change on the cross section of the rectangular cell, dictates the border between the zones.

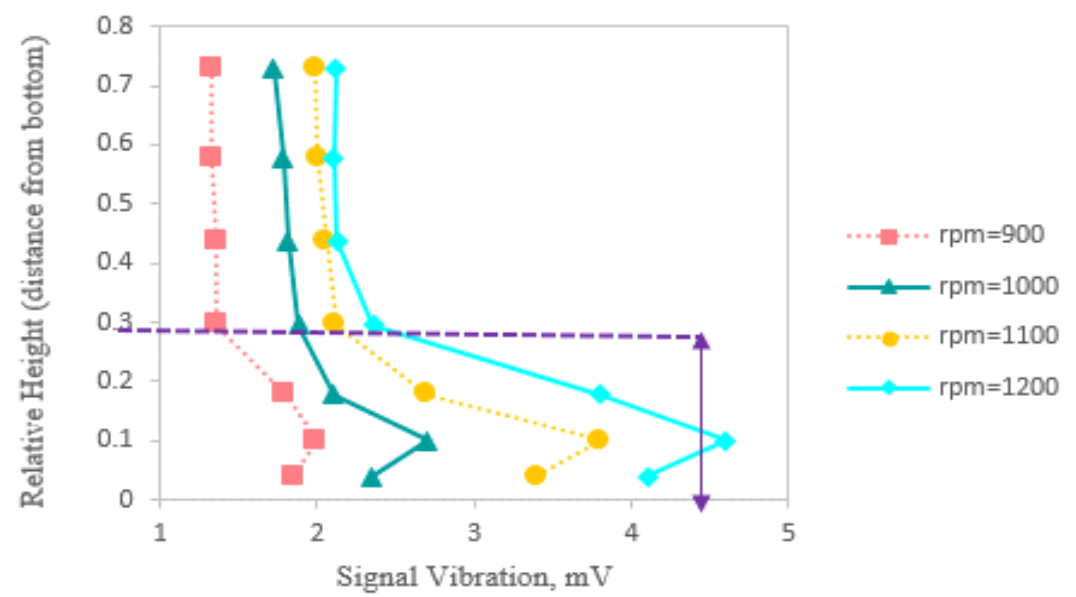

Figure5. Vibration signal profiles at different impeller speeds in the rectangular cell A

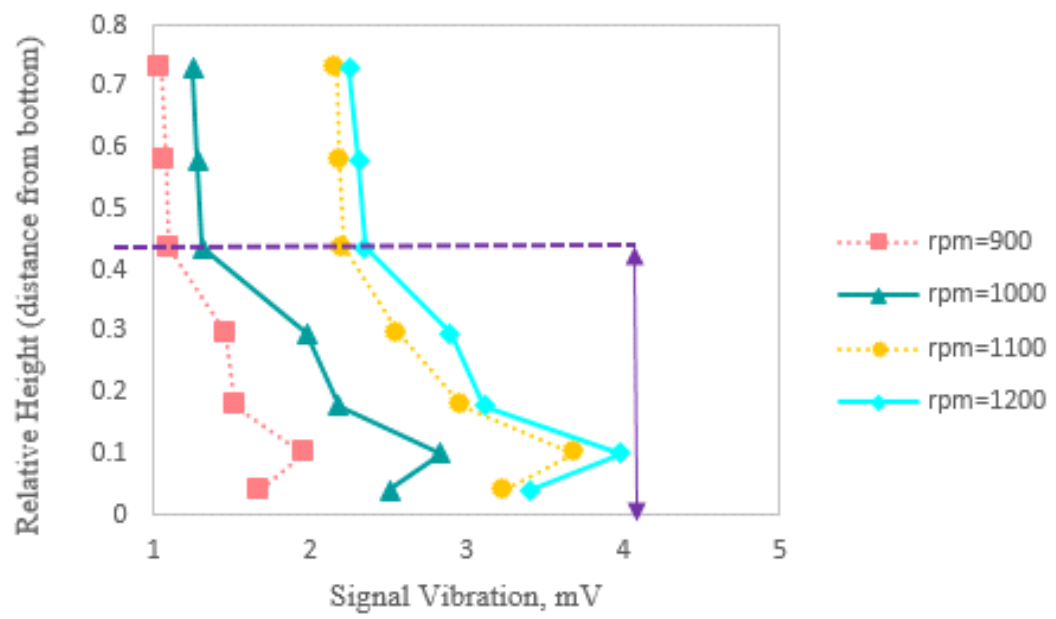

Figure6. Vibration signal profiles at different impeller speeds in the rectangular cell B 


\section{CONClusions}

The portion of turbulent and quiescent zones in a mechanical flotation cell plays an important role on the recovery of targeted and gangue minerals by true flotation and entrainment, as turbulence affects the collision, attachment and detachment, while quiescent zone inhibits the entrainment. Therefore, an optimized portion of these zones could ameliorate the flotation process. Although the effects of some variables such as impeller speed and size, cell aspect ratio and superficial gas velocity on the height of turbulent and quiescent zones have been studied before, the main variable of cell cross-section, which seems to control the zones' border, was ignored in the previous studies. In this study, three different geometries were considered and the turbulence was measured using a piezo electric sensor. Results showed that in the cell with constant cross section, the height of the turbulent zone has strong dependence on the impeller speed while in cells with variable cross sections, the height of the turbulent zone is independent of impeller speed and it is related to the point that the cross section changes. Therefore, this point is the boundary of turbulent and quiescent zones. Since selection of an optimized portion of turbulent and quiescent zones is a critical factor in the performance of mechanical flotation cells, attention to geometry (cross-section) of cells is essential.

\section{REFERENCES}

[1] Boeree, C., Up-scaling of froth flotation equipment. 2014.

[2] Gorain, B., J. Franzidis, and E. Manlapig, Flotation Cell Design: Application of Fundamental Principles. 2000.

[3] Zhou, G. and S.M. Kresta, Impact of tank geometry on the maximum turbulence energy dissipation rate for impellers. AIChE journal, 1996. 42(9): p. 2476-2490.

[4] Tabosa, E., et al., Improving flotation energy efficiency by optimizing cell hydrodynamics. Minerals Engineering, 2016. 96-97: p. 194-202.

[5] Meng, J., et al., Measuring turbulence in a flotation cell using the piezoelectric sensor. Minerals Engineering, 2014. 66-68: p. 84-93.

\section{AUTHORS' BIOGRAPHY}

Sima Razmjooei, $\mathrm{PhD}$ candidate in mineral processing, Mineral processing Group, Department of Mining, Faculty of Engineering TarbiatModares University, Islamic Republic of Iran

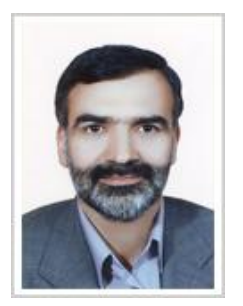

Dr. Mahmoud Abdollahy, Professor, Mineral processing Group, Department of Mining, Faculty of Engineering TarbiatModares University, Islamic Republic of Iran.

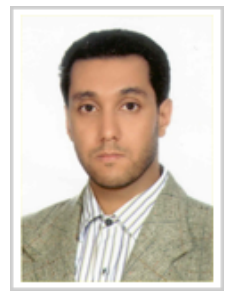

Dr. Mohammad Reza Khalesi, Assistant Prof, Mineral processing Group, Department of Mining, Faculty of Engineering TarbiatModares University Islamic Republic of Iran

Mehdi Mohseni, PhD student in mineral processing, Mineral processing Group, Department of Mining, Faculty of Engineering TarbiatModares University, Islamic Republic of Iran

Citation: M. Abdollahy et al. (2017). The Effect of Cross Section of Mechanical Flotation Cells on the Height of Turbulent and Quiescent Zones, International Journal of Mining Science (IJMS), 3(4), pp.89-92, DOI: http://dx.doi.org/ 10.20431/2454-9460.0304008.

Copyright: (C) 2017 M. Abdollahy. This is an open-access article distributed under the terms of the Creative Commons Attribution License, which permits unrestricted use, distribution, and reproduction in any medium, provided the original author and source are credited 